\title{
The gastroprotective effect of obestatin on indomethacin-induced acute ulcer is mediated by a vagovagal mechanism
}

\author{
LEYLA SEMIHA ŞEN ${ }^{1,3}$ @ , ZARIFE NIGAR ÖZDEMIR KUMRAL ${ }^{1}$ (D), \\ GÜLSÜN MEMI ${ }^{1}$ (D), FERIHA ERCAN ${ }^{2}$ (D), BERRAK C. YEGEN ${ }^{1 *}$ (1) and \\ CUMHUR YEĞEN ${ }^{3}$
}

\footnotetext{
${ }^{1}$ Department of Physiology, Marmara University School of Medicine, İstanbul, Turkey

${ }^{2}$ Department of Histology \& Embryology, Marmara University School of Medicine, İstanbul, Turkey

${ }^{3}$ Department of General Surgery, Marmara University School of Medicine, İstanbul, Turkey
}

Received: July 3, 2019 • Accepted: February 17, 2020

Published online: July 17, 2020

(๔ 2020 Akadémiai Kiadó, Budapest

\begin{abstract}
In order to investigate the role of the vagus nerve in the possible gastroprotective effect of obestatin on the indomethacin-induced acute oxidative gastric injury, Sprague-Dawley rats of both sexes were injected subcutaneously with indomethacin $\left(25 \mathrm{mg} / \mathrm{kg}, 5 \% \mathrm{NaHCO}_{3}\right)$ followed by obestatin $(10,30$ or $100 \mu \mathrm{g} / \mathrm{kg})$. In other sets of rats, surgical vagotomy $(\mathrm{Vx})$ or selective degeneration of vagal afferent fibers by perivagal capsaicin was performed before the injections of indomethacin or indomethacin + obestatin $(30 \mu \mathrm{g} / \mathrm{kg})$. Gastric serosal blood flow was measured, and $4 \mathrm{~h}$ after ulcer induction gastric tissue samples were taken for histological and biochemical assays. Obestatin reduced the severity of indomethacin-induced acute ulcer via the reversal of reactive hyperemia, by inhibiting ulcer-induced neutrophil infiltration and lipid peroxidation along with the replenishment of glutathione (GSH) stores, whereas $\mathrm{Vx}$ abolished the inhibitory effect of obestatin on blood flow and lipid peroxidation, and worsened the severity of ulcer. On the other hand, serosal blood flow was even amplified by the selective denervation of the capsaicin-sensitive vagal afferent fibers, but obestatin-induced reduction in ulcer severity was not altered. In conclusion, the gastroprotective effect of obestatin on indomethacin-induced ulcer appears to involve the activation of the vagovagal pathway.
\end{abstract}

\section{KEYWORDS}

NSAID, obestatin, vagus, neutrophil, capsaicin, hyperemia, indomethacin

\footnotetext{
* Corresponding author. Department of Physiology, Marmara University School of Medicine, Başbüyük Mah. Maltepe Başıbüyük Yolu No. 9/1, Maltepe, 34854, İstanbul, Turkey. Tel.: +90 216777 5657, E-mail: byegen@ marmara.edu.tr
} 


\section{INTRODUCTION}

The use of non-steroidal anti-inflammatory drugs (NSAID), which are prescribed widely for their analgesic and anti-inflammatory properties, is increased due to newly defined indications in the aging world population. The most common side effects of NSAIDs are observed throughout the entire gastrointestinal tract, and include dyspeptic complaints of varying severity, bleeding or perforation of gastric and duodenal ulcers [1]. When the balance between the factors that prevent or facilitate gastric mucosal damage (e.g. luminal factors, resistance of epithelial cells, subepithelial microcirculation, afferent sensory neurons and mucosal immune system) is impaired, gastric mucosal damage is inevitable. The dense gastric capillary network maintains the mucus and bicarbonate barrier, removes the back-diffused toxins and hydrogen ions and provides oxygen and necessary nutrients for the viability of epithelial cells. When the mucosa is exposed to an irritating substance or when there is hydrogen back-diffusion, a rapid increase in the mucosal blood flow occurs due to the release of calcitonin gene related peptide (CGRP) from the submucosal afferent sensory neurons and the subsequent release of the vasodilator nitric oxide (NO) from the endothelia of the submucosal arteries [2-4]. In contrary, application of capsaicin to afferent sensory neurons eliminates the gastric hyperemic response and mucosal damage occurs [5]. Ulcer healing accelerates when mucosal blood flow increases [6]. A growing body of evidence has demonstrated that stimulation of the vagal afferent fibers found in the mucosal and submucosal layers of the digestive tract [7] activates a cholinergic anti-inflammatory reflex, by which the efferent pathway inhibits the release of cytokines and prevents tissue damage in several inflammatory models [8-10]. On the other hand, vagotomy was shown to elevate the levels of inflammatory cytokines and enhance the severity of colonic inflammation [11, 12].

Obestatin, a 23-amino acid peptide hormone derived from the precursor protein preproghrelin, is distributed in several tissues including the stomach and intestines [13]. Apart from its controversial effects on food intake [14], obestatin was shown to exert anti-inflammatory effects in several inflammatory models [15-17]. Despite the fact that gastric ulcer patients with Helicobacter pylori infection had similar serum obestatin levels as $H$. pylori-negative patients [18], bacterial eradication resulted in elevated serum obestatin levels [19], suggesting a gastroprotective role of obestatin. In a chronic gastric ulcer model induced with topical acetic acid application on the gastric serosa, obestatin was shown to accelerate ulcer healing by increasing mucosal blood flow and decreasing the expression of pro-inflammatory cytokines in the gastric mucosa [20]. However, the involvement of the vagus nerve in the putative gastroprotective effect of obestatin has not been elucidated.

In the light of all the above mentioned studies, we aimed to investigate the role of the vagus nerve in the gastroprotective impact of obestatin on NSAID-induced acute oxidative gastric injury in rats.

\section{MATERIALS AND METHODS}

\section{Animals}

Sprague-Dawley rats of both sexes (10-week-old, 280-320 g) were supplied by the Marmara University (MU) Animal Center (DEHAMER) and were housed in an air-conditioned room with 12 -h light and dark cycles, where the temperature $\left(22 \pm 2{ }^{\circ} \mathrm{C}\right)$ and relative humidity (65-70\%) were kept constant. Rats were fed with standard laboratory chow and had free access 
A

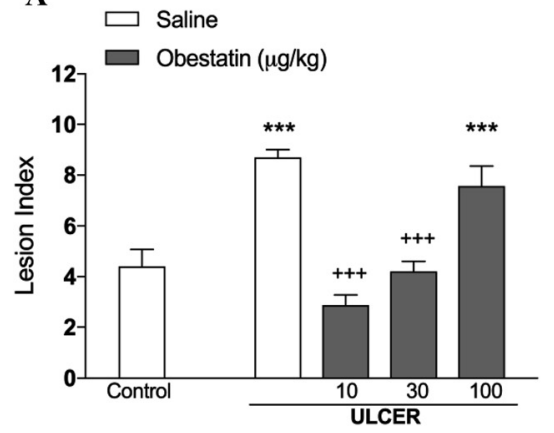

B

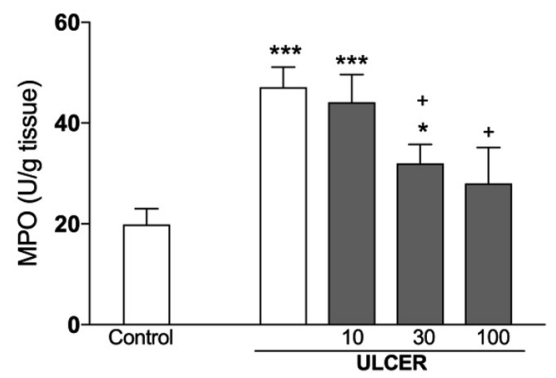

Fig. 1. A) Histological lesion index, B) Myeloperoxidase (MPO) activity in gastric tissue; ${ }^{\star} P<0.05,{ }^{\star \star \star} P<0.001$ compared to non-ulcer control group, $+P<0.05,+++P<0.001$ compared to saline-treated ulcer group

to water. All experimental protocols were approved by the MU Animal Care and Use Committee (approval number: 15.2010.mar.)

\section{Experimental design and surgery}

After overnight fasting, indomethacin (25 mg/kg in $5 \% \mathrm{NaHCO}_{3}$; Sigma-Aldrich, Missouri, USA) was injected subcutaneously (s.c.) for the induction of acute gastric ulcer, while the non-ulcer control groups received $\mathrm{NaHCO}_{3}(1 \mathrm{ml} / \mathrm{kg}$, s.c). In order to determine the effective dose of obestatin in alleviating gastric injury, rats were treated with one of the three doses $(10,30$ or $100 \mu \mathrm{g} / \mathrm{kg}$ in saline; intraperitoneally, i.p.) of obestatin 15 min after the indomethacin injection $(n=8$ in each group), while the vehicle-treated ulcer $(n=8)$ and control $(n=8)$ groups were given saline. The mid-dose $(30 \mu \mathrm{g} / \mathrm{kg})$ was chosen for the rest of the experiments, because this intermediate dose was efficient in both suppressing ulcer-induced neutrophil infiltration and high ulcer score (Fig. 1).

In another set of animals $(n=24)$, surgical vagotomy $(\mathrm{Vx})$ was performed to evaluate the contribution of the vagal pathway in the gastroprotection afforded by obestatin. On the 8th day after $\mathrm{Vx}$, rats were treated with indomethacin or indomethacin plus obestatin $(30 \mu \mathrm{g} / \mathrm{kg})$ or $\mathrm{NaHCO}_{3}$ (control-Vx). In order to differentiate the role of vagal afferent fibers in the gastroprotective action of obestatin, selective degeneration of vagal afferent fibers was performed in a third group of rats $(n=16)$. On the 8 th day following perivagal capsaicin application, rats were treated with indomethacin or indomethacin plus obestatin $(30 \mu \mathrm{g} / \mathrm{kg})$.

One hour after the indomethacin or $\mathrm{NaHCO}_{3}$ injection, all rats were anesthetized for the measurement of gastric serosal blood flow and were decapitated $3 \mathrm{~h}$ later. Macroscopic lesion indices were recorded, gastric tissue samples were obtained for the measurement of myeloperoxidase (MPO) activity and malondialdehyde (MDA) and glutathione (GSH) levels, and extra tissues were placed in formaldehyde solution for histological examinations.

\section{Vagotomy (Vx)}

Under aseptic conditions, rats were anesthetized with a combination of ketamine $(100 \mathrm{mg} / \mathrm{kg})$ and xylazine $(10 \mathrm{mg} / \mathrm{kg})$ given in an i.p. injection. After a midline incision, gastric $\mathrm{Vx}$ was 
performed by transection of the dorsal vagal trunk just under the diaphragm, and the hepatic and celiac branches of the ventral vagus nerve and the ventral gastric nerve filament were also transected at the region close to the stomach [21]. The incision was closed; the rats were returned to their cages and monitored for a week until the injection of indomethacin or $\mathrm{NaHCO}_{3}$ on the 8th day, which was followed by obestatin or saline administration.

\section{Capsaicin application onto the vagus nerve}

Under ketamine and xylazine anesthesia, tracheostomy was performed and a tracheal tube was inserted through which the animals breathed room air spontaneously. In order to decrease the acute respiratory and cardiovascular effects of capsaicin, rats were pretreated with atropine sulfate $(2 \mathrm{mg} / \mathrm{kg}$, i.p.). After a midline incision, the sub-diaphragmatic vagal trunks (both anterior and posterior) were exposed between the diaphragm and the gastric cardia. Then, to perform vagal afferent denervation, a $1 \%$ solution of capsaicin (in $10 \%$ ethanol, $10 \%$ Tween 80 , and $80 \%$ saline $0.9 \%$; Sigma-Aldrich) was applied topically onto the vagus nerve by a soaked swab, while the underlying tissues were protected by a layer of parafilm. The application was continued for $30 \mathrm{~min}$ and the total capsaicin dose did not exceed $1 \mathrm{mg} / \mathrm{rat}$ [22]. The vagal area was rinsed with sterile saline to remove capsaicin, and the incision was closed. In the sham group, vehicle (Tween 80 in saline and ethanol) was applied onto the vagus nerve for $30 \mathrm{~min}$ before the closure of the incision. The rats were returned to their cages and observed for a week. On the 8 th day, capsaicin-treated and sham rats were tested by applying $1 \% \mathrm{NH}_{4} \mathrm{OH}$ solution into the eye. The absence of the eye-wiping response verified that the corneal afferents were impaired and lacked chemosensitivity [23]. Then, obestatin $(30 \mu \mathrm{g} / \mathrm{kg})$ or saline was applied immediately after the injection of indomethacin or $\mathrm{NaHCO}_{3}$.

\section{Measurement of serosal blood flow}

The gastric serosal blood flow was evaluated using a laser-Doppler flowmeter (PeriFlux System 5000, Perimed, Sweden). For the recording of gastric blood flow, all rats were anesthetized (ketamine plus xylazine) 1 hour after the indomethacin or $\mathrm{NaHCO}_{3}$ injection. The laser probe was inserted through a small cannula and fixed in position with a stabilizer on the corpus of the stomach to record for $40 \mathrm{~min}$. Following an initial 30-min period of stabilization, the average flow within a 10-min period was used to express the blood flow in terms of perfusion unit (PU) [24].

\section{Lesion index}

Four hours after the indomethacin or $\mathrm{NaHCO}_{3}$ injection, rats were decapitated and the dissected stomachs were cut along the greater curvature. For the macroscopic analysis of hemorrhagic lesions, the mucosa was rinsed with normal saline. The length (millimeter) of each lesion was measured, summed per stomach, and expressed as ulcer index, in which three petechia were counted as $1 \mathrm{~mm}$.

\section{Measurementof myeloperoxidase (MP0) activity}

MPO is an enzyme found mainly in the azurophilic granules of polymorphonuclear leukocytes $(\mathrm{PMN})$. Since tissue MPO activity has a positive correlation with the number of PMN 
determined histochemically in the tissues, it is frequently used for the estimation of PMN accumulation in inflamed tissue areas [25]. MPO activity was measured according to the modified method of Hillegass et al. [26]. Gastric samples were homogenized in $50 \mathrm{mM}$ potassium phosphate buffer (KPB, pH 6.0) and centrifuged at 41,400 g (10 min); pellets were suspended in $50 \mathrm{mM} \mathrm{KPB}$ containing $0.5 \%$ hexadecyltrimethylammonium bromide (HETAB). After three freeze and thaw cycles, with sonication between cycles, the samples were centrifuged at $41,400 \mathrm{~g}$ for $10 \mathrm{~min}$. Aliquots $(0.1 \mathrm{~mL})$ were added to $2.9 \mathrm{~mL}$ of reaction mixture containing $50 \mathrm{mM} \mathrm{KPB}$, o-dianisidine and $20 \mathrm{mM} \mathrm{H}_{2} \mathrm{O}_{2}$. One unit of enzyme activity was defined as the amount of MPO that caused a change in absorbance measured at $460 \mathrm{~nm}$ for $3 \mathrm{~min}$. MPO activity was expressed as $\mathrm{U} / \mathrm{g}$ tissue.

\section{Measurement of malondialdehyde (MDA) and glutathione (GSH) levels}

Gastric tissue samples obtained from each animal were stored at $-70{ }^{\circ} \mathrm{C}$ for the measurement of MDA and GSH levels. Gastric tissue samples were homogenized with ice-cold trichloroacetic acid (10\%) using an Ultra Turrax tissue homogenizer. MDA levels were assayed on the basis of products of lipid peroxidation by monitoring thiobarbituric acid reactive substance formation. Lipid peroxidation was expressed in terms of MDA equivalents in gram tissue. GSH measurements were performed using a modification of the Ellman procedure. Briefly, after centrifugation, the supernatant was added to $\mathrm{Na}_{2} \mathrm{HPO}_{4} \cdot 2 \mathrm{H}_{2} \mathrm{O}$ solution. $0.2 \mathrm{~mL}$ of dithiobisnitrobenzoate solution $(0.4 \mathrm{mg} / \mathrm{mL}$ in $1 \%$ sodium citrate) was added and immediately after mixing, the absorbance was measured at $412 \mathrm{~nm}$ [15].

\section{Light microscopic preparation and analysis}

Ulceration was quantified by light microscopic analysis. Samples from the corpus of the stomach were placed in $10 \%$ formaldehyde and processed by routine techniques before embedding in paraffin. Tissue sections $(4 \mu \mathrm{m})$ were stained with hematoxylin and eosin (H\&E) and examined under an Olympus BX51 photomicroscope (Tokyo, Japan). Gastric injury was assessed semiquantitatively using the criteria previously described by an experienced histologist (F.E.) blinded to the treatments of the experimental groups: Desquamation of surface epithelium (0-3, where 0 , None; 1, Mild; 2, Moderate; 3, Severe), Hemorrhage, focal necrosis and mucosal congestion (0-3), Degeneration of glandular cells (0-3), Inflammatory cell infiltration (0-3), with a maximum score of 12 [27].

\section{Statistical analysis}

Statistical analysis was carried out using GraphPad Prism 8.0.2 (GraphPad Software, San Diego, $\mathrm{CA})$. The results are expressed as means \pm SEM. Data were compared by one-way analysis of variance (ANOVA) followed by Tukey-Kramer Post-hoc test. Differences were considered statistically significant when $P<0.05$.

\section{RESULTS}

The initial dose-response study for obestatin revealed that the increased ulcer index in salinetreated ulcer as compared to the control group $(P<0.001)$ was depressed significantly by $10 \mu \mathrm{g} / \mathrm{kg}$ 
A

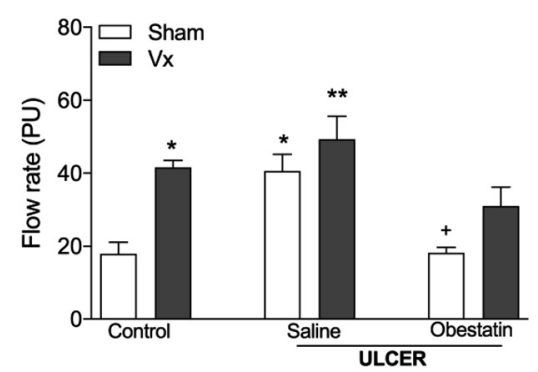

C

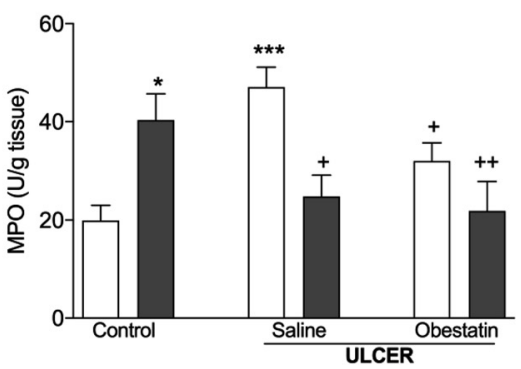

B

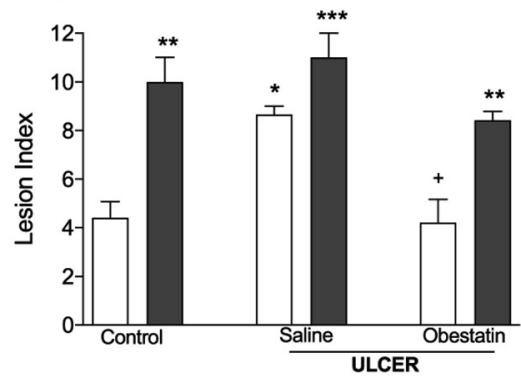

D

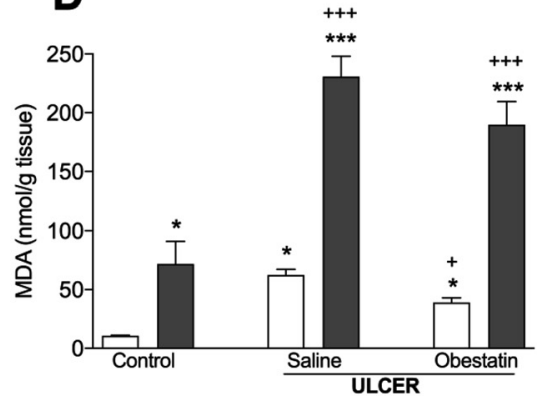

E

Fig. 2. A) Mean blood flow rate measured by laser Doppler from the gastric serosal surface and given as perfusion unit (PU), B) Histological lesion index, C) Myeloperoxidase (MPO) activity, D) Malondialdehyde (MDA) and E) Glutathione (GSH) levels; ${ }^{\star} P<0.05,{ }^{* \star} P<0.01$, ${ }^{\star * *} P<0.001$ compared to non-ulcer control group, $+P<0.05,++P<0.01,+++P<0.001$ compared to sham-operated ulcer group. In each subgroup $n=8, \mathrm{Vx}=$ vagotomy

and $30 \mu \mathrm{g} / \mathrm{kg}$ doses of obestatin $(P<0.001)$, but not by the $100 \mu \mathrm{g} / \mathrm{kg}$ dose (Fig. 1$)$. On the other hand, elevated gastric MPO activity $(P<0.001)$ in the saline-treated ulcer group was decreased by both $30 \mu \mathrm{g} / \mathrm{kg}$ and $100 \mu \mathrm{g} / \mathrm{kg}$ doses $(P<0.05)$. Based on these results, the $30 \mu \mathrm{g} / \mathrm{kg}$ dose of obestatin was chosen to be used in the rest of the experiments. In the saline-treated ulcer group, as compared to the control group, serosal blood flow and gastric MDA level were also increased, 

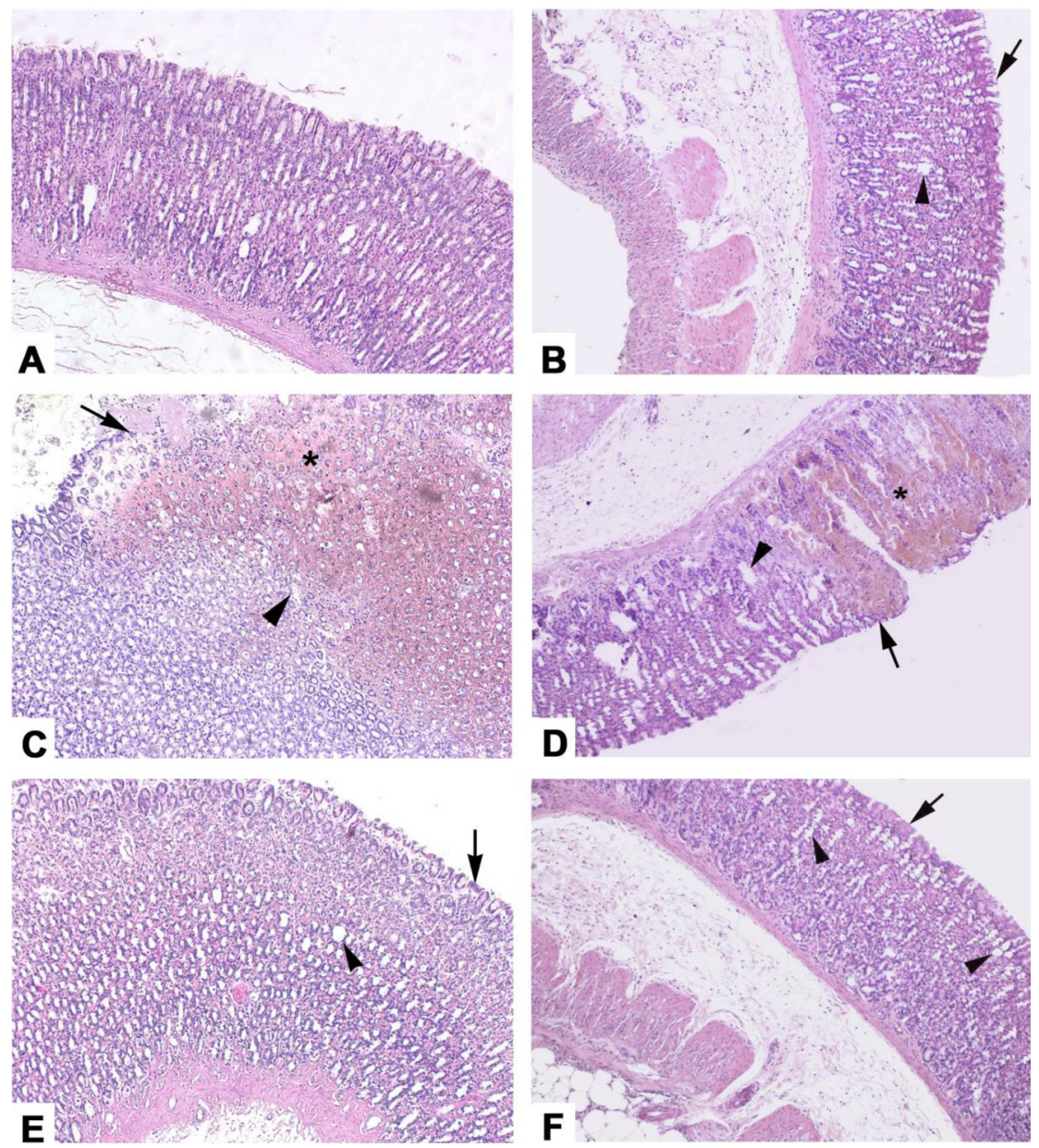

Fig. 3. A) Representative light micrographs of experimental groups. Regular gastric mucosa with surface and glandular epithelium in the control group (A). Quite regular surface epithelium (arrow) and mild dilatation in glands (arrow head) in the saline-treated control group with vagotomy (B). Severe degeneration of surface (arrow) and glandular (arrow head) epithelium and bleeding in mucosa $\left(^{*}\right.$ ) in indomethacin-treated ulcer (C) and indomethacin-treated ulcer plus vagotomy (D) groups. Quite regular surface epithelium (arrow) and mild dilatation in glands (arrow head) in obestatin-treated ulcer group (E) and obestatin-treated ulcer group with vagotomy $(\mathrm{F})$. H\&E staining. Original magnification: $\times 100$

whereas gastric GSH was depleted $(P<0.05$; Fig. 2$)$. The $30 \mu \mathrm{g} / \mathrm{kg}$ dose of obestatin reversed these changes significantly $(P<0.05)$.

In the non-ulcer control rats, $\mathrm{Vx}$ resulted in changes similar to those of the saline-treated indomethacin-ulcer group. As observed in the saline-treated ulcer group, blood flow, lesion index, gastric MDA and MPO levels were all elevated in the control rats with $\mathrm{Vx}(P<0.05-0.01)$, but no change was observed in the GSH level (Fig. 2). When Vx rats were induced with ulcer, neither the elevated blood flow nor the high lesion index was different from that of the ulcer 
A

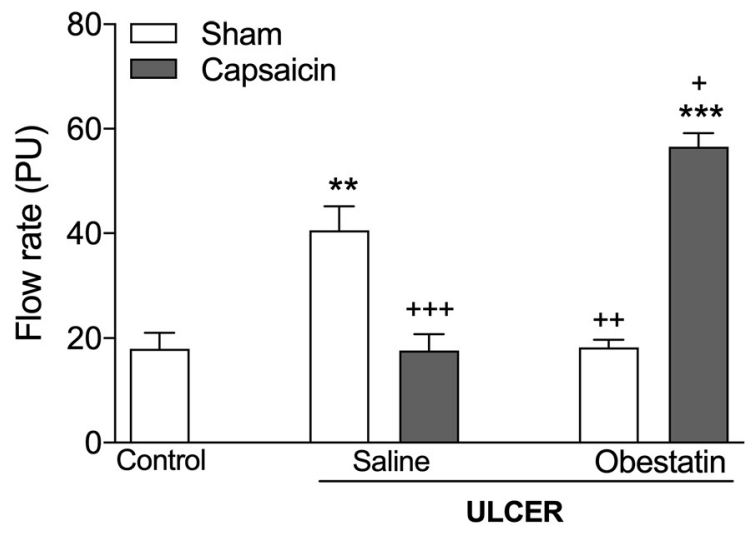

B

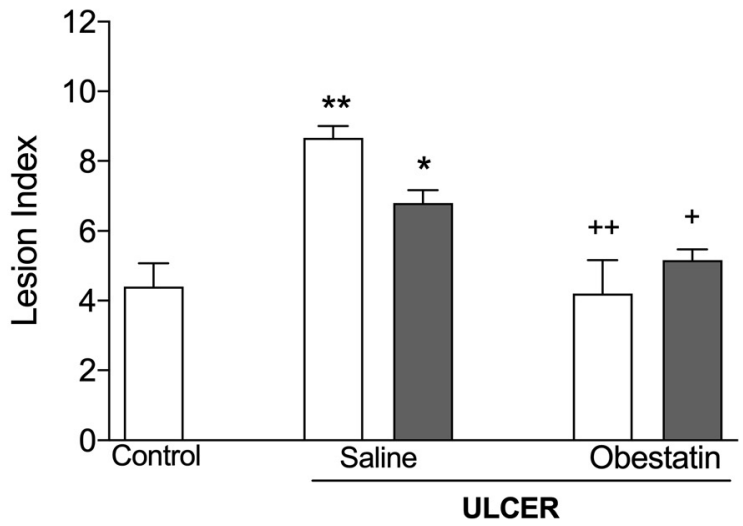

Fig. 4. A) Mean blood flow rate measured by laser Doppler from the gastric serosal surface and given as perfusion unit (PU), B) Histological lesion index, ${ }^{\star} P<0.05,{ }^{* *} P<0.01$, ${ }^{* *} P<0.001$ compared to non-ulcer control group, $+P<0.05,++P<0.01,+++P<0.001$ compared to sham (vehicle of capsaicin was applied) ulcer group. In each subgroup $n=8$

group with intact vagi. However, Vx prior to ulcer induction further elevated the MDA level, aggravating the ulcer-induced lipid peroxidation, which was accompanied by an increased GSH content $(P<0.001)$. On the other hand, ulcer-induced elevation of gastric MPO activity was pushed back to control levels in Vx-rats with ulcer $(P<0.05)$. Obestatin-induced reductions in 
gastric blood flow, lesion index and MDA as compared to saline-treated ulcer rats were abolished when rats were previously vagotomized $(P<0.05-0.01)$, suggesting the role of vagal innervation in the gastroprotective effects of obestatin. However, obestatin-induced reduction in MPO or replenishment in GSH was not affected by Vx.

Histological evaluation revealed a regular gastric mucosa in the control group (Fig. 3A), but a quite regular surface epithelium with a mild dilatation of glands was observed in the control group with $\mathrm{Vx}$ (Fig. 3B). In the saline-treated ulcer group with intact vagi (Fig. 3C), severe damage of the surface mucous cells and gastric pits was noticed, while dilated and mostly degenerated glandular cells, severe inflammatory cell infiltration and mucosal hemorrhage were evident. In the saline-treated ulcer group with Vx (Fig. 3D), severe degeneration of surface epithelium, severe dilatation of glands and mucosal bleeding were observed. On the other hand, regular surface mucosal cells and gastric pits along with a moderate damage of glandular cells and inflammatory cell infiltration were observed in the obestatin-treated ulcer group with intact vagi (Fig. 3E). The obestatin-treated ulcer group with Vx (Fig. 3F) showed a quite regular surface epithelium and mild dilatation of glands.

In order to differentiate the contribution of vagal afferents in obestatin-induced gastroprotection afforded by the vagus nerve, capsaicin-induced vagal afferent denervation was accomplished. In contrast to truncal vagotomy, afferent denervation in the ulcerated stomach resulted in a decrease in blood flow back to control levels $(P<0.001 ;$ Fig. 4$)$. On the other hand, the inhibitory effect of obestatin on ulcer-induced high blood flow was abolished and increased by 3 -fold in the afferent-denervated group. However, in contrary to total Vx, obestatin-induced alleviation of ulcer severity was not modified solely by afferent denervation, suggesting the additional role of the vagal efferent pathway in obestatin's gastroprotective property.

\section{DISCUSSION}

The results demonstrate that obestatin reduced the severity of indomethacin-induced acute ulcer via the reversal of reactive hyperemia, inhibition of ulcer-induced neutrophil infiltration and lipid peroxidation along with the replenishment of GSH stores. Vagotomy abolished the inhibitory effect of obestatin on blood flow and lipid peroxidation, and thereby worsened the ulcer severity. Although obestatin-induced reduction in ulcer severity was not altered by the selective denervation of the capsaicin-sensitive vagal afferent fibers, inhibition of blood flow by obestatin was abolished and the flow was even amplified in the absence of afferent innervation. Thus, our findings suggest that the gastroprotective effect of obestatin on indomethacin-induced ulcer involves the activation of the vagovagal pathway.

It is well described that NSAIDs increase mucosal permeability, cause neutrophil infiltration and adhesion and enhance the formation of reactive oxygen species (ROS), which result in the oxidation of important biomolecules (e.g. lipid, protein and DNA) along with a reduction in antioxidant molecules [28-31]. However, it was shown that when circulating neutrophils were depleted, NSAID-induced gastric damage was significantly improved, implicating that marginalization of circulating neutrophils is critical in the pathogenesis of NSAID-induced gastropathy. Accordingly, our results revealed that the increased ulcer index and elevated gastric MDA level due to indomethacin administration were alleviated by obestatin treatment, whereas MPO activity was depressed, suggesting that the anti-ulcer action of obestatin involves the 
inhibition of neutrophil infiltration. Similarly, in several other inflammatory models the antiinflammatory and anti-oxidant effects of obestatin were associated with the inhibition of neutrophil infiltration to the affected tissues [15-17, 32]. In parallel, the acceleratory effect of repetitive obestatin treatment on chronic ulcer healing was attributed to its inhibitory action on the expression of mucosal pro-inflammatory cytokines, which are dominantly released by the invading neutrophils [20]. In a recent study, obestatin given at the same dose as in our study was shown to alleviate indomethacin-induced acute gastric ulcer by reducing gastric acid secretion, increasing gastric nitric oxide level and by up-regulating the expression of vascular endothelial growth factor (VEGF) [24]. Our findings revealed that a single injection of obestatin also protected against indomethacin-induced acute gastric ulcer via the inhibition of neutrophil infiltration. Although our results showed that vagotomy in the control rats increased the accumulation of neutrophils, which are known to be suppressed by vagal stimulation [33], obestatin-induced suppression of neutrophil recruitment to the ulcerated stomach was not changed by vagotomy. Thus, as it is observed in other inflamed tissues, obestatin provides gastroprotection by limiting the infiltration of neutrophils and replenishing GSH stores, which were depleted upon ulceration. On the other hand, these effects of obestatin were still evident in the absence of gastric vagal innervation, indicating that this gastroprotective mechanism is independent of the vagal anti-inflammatory pathway. However, destruction of gastric vagal innervation amplified ulcer severity and gastric lipid peroxidation, which were alleviated by obsestatin. Accordingly, depression of serosal blood flow by obestatin treatment was abolished by vagal afferent denervation or total vagotomy, suggesting that the gastroprotective effect of obestatin involves its modulatory role on gastric microcirculation via the vagovagal pathway.

A disturbed mucosal microcirculation was proposed to have a crucial role in the pathogenesis of acute gastric ulceration, including those induced by NSAIDs [34, 35]. In patients with active gastric ulcers, gastric mucosal blood flow (GMBF) was significantly decreased in most of the gastric regions, but significantly higher GMBF values were observed around the healing ulcer than in the surrounding normal mucosa [36]. In several studies conducted in rats, development of gastric mucosal lesions by NSAID administration was associated with gastric hypermotility, which resulted in reduced GMBF and increased neutrophil-endothelial interaction [30]. However, in our study serosal blood flow was significantly increased $1 \mathrm{~h}$ after the indomethacin treatment, which reflects a reactive hyperemia in response to the acute injurious effect of indomethacin. Since the enhanced serosal blood flow is accompanied by increased neutrophil infiltration and gastric injury, it suggests that the immediate rush of blood is involved in the generation of acute indomethacin damage. Similar hyperemic responses with increased mucosal and serosal blood flow measurements were obtained when the gastric mucosa was exposed to an acidic solution [37]. Moreover, our results revealed that obestatin, when administered prior to indomethacin, alleviated ulcer with a concomitant inhibitory effect on ulcer-induced increase in blood flow, which was reversed back to control level. However, in an acetic acid-induced chronic ulcer model, which also resulted in increased mucosal blood flow, obestatin further augmented gastric mucosal blood flow [20]. Taken together with the aforementioned studies, it may be proposed that obestatin modifies the disturbed gastric microcirculation, which may be increased or decreased at different time points of ulcerogenesis. Moreover, present findings further suggest that the modulatory effect of obestatin on gastric blood flow of the ulcerated stomach is mediated by the vagus nerve and depends specifically on the intactness of vagal afferents. 
Extensive evidence supports that protection against gastric mucosal damage due to various agents requires the integrity of capsaicin-sensitive splanchnic afferents, whereas Vx aggravates the damage by eliminating the beneficial effects of these gastroprotective substances [38-40]. In our indomethacin-induced acute ulcer model, the anti-ulcer effects of obestatin were partially reversed by vagotomy, which aggravated the gastric injury with a concomitant enhancement in lipid peroxidation. On the other hand, selective denervation of the vagal afferents abolished the inhibitory effect of obestatin on ulcer-induced hyperemia. In parallel with these results, either vagotomy or capsaicin denervation was reported to attenuate the gastroprotective effects of ghrelin, which is derived from the same precursor as obestatin $[5,41]$. Previously it was shown that the stimulatory effect of obestatin on pancreatic secretion and its inhibitory effect on gastroduodenal motility were mediated via the vagus nerve $[42,43]$. Taken together with our results, it may be speculated that the regulatory effect of obestatin under both physiological and pathophysiological conditions involves the activation of the vagovagal pathway. Although the presence of ghrelin receptors on the vagal afferents have already been demonstrated [23], further studies are required to elucidate the existence of obestatin receptors on the vagal afferents.

In conclusion, the results of the present study revealed for the first time that even a single dose of obestatin is effective in alleviating indomethacin-induced acute gastric ulcer through a vagovagal mechanism. Thus, obestatin, which has been shown to have protective effects under various inflammatory conditions, may be a highly promising agent to prevent the occurrence of NSAID-related gastropathy when given in conjunction with NSAID intake.

Conflict of interest: The authors declare there is no conflict of interest.

\section{ACKNOWLEDGMENT}

This research work was supported by a grant from the Marmara University Fund (SAG-A080410-0064). The authors are grateful to Dr. Demir Kıran for his technical assistance.

\section{REFERENCES}

1. Russell RI. Non-steroidal anti-inflammatory drugs and gastrointestinal damage-problems and solutions. Postgrad Med J 2001; 77: 82-8.

2. Bruggeman TM, Wood JG, Davenport HW. Local control of blood flow in the dog's stomach: vasodilatation caused by acid back-diffusion following topical application of salicylic acid. Gastroenterology 1979; 77: 736-44.

3. Li DS, Raybould HE, Quintero E, Guth PH. Calcitonin gene-related peptide mediates the gastric hyperemic response to acid back-diffusion. Gastroenterology 1992; 102: 1124-8.

4. Lippe IT, Holzer P. Participation of endothelium-derived nitric-oxide but not prostacyclin in the gastricmucosal hyperemia due to acid back-diffusion. Br J Pharmacol 1992; 105: 708-14.

5. Brzozowski T, Konturek PC, Sliwowski Z, Pajdo R, Drozdowicz D, Kwiecien S, et al. Prostaglandin/cyclooxygenase pathway in ghrelin-induced gastroprotection against ischemia-reperfusion injury. J Pharmacol Exp Ther 2006; 319: 477-87. 
6. Sato N, Kawano S, Tsuji S, Ogihara T, Yamada S. Gastric blood flow in ulcer diseases. Scand J Gastroenterol 1995; 208: 14-20.

7. Berthoud HR, Neuhuber WL. Functional and chemical anatomy of the afferent vagal system. Auton Neurosci 2000; 85: 1-17.

8. Meregnani J, Clarencon D, Vivier M, Peinnequin A, Mouret C, Sinniger V, et al. Anti-inflammatory effect of vagus nerve stimulation in a rat model of inflammatory bowel disease. Auton Neurosci 2011; 160: 82-9.

9. Sun P, Zhou K, Wang S, Li P, Chen S, Lin G, et al. Involvement of MAPK/NF-kappaB signaling in the activation of the cholinergic anti-inflammatory pathway in experimental colitis by chronic vagus nerve stimulation. PLoS One 2013; 8: e69424.

10. Tracey KJ. Physiology and immunology of the cholinergic antiinflammatory pathway. J Clin Invest 2007; 117: 289-96.

11. Di Giovangiulio M, Bosmans G, Meroni E, Stakenborg N, Florens M, Farro G, et al. Vagotomy affects the development of oral tolerance and increases susceptibility to develop colitis independently of the alpha-7 nicotinic receptor. Mol Med 2016; 22: 464-76.

12. Ghia JE, Blennerhassett P, Kumar-Ondiveeran H, Verdu EF, Collins SM. The vagus nerve: a tonic inhibitory influence associated with inflammatory bowel disease in a murine model. Gastroenterology 2006; 131: 1122-30.

13. Gronberg M, Tsolakis AV, Magnusson L, Janson ET, Saras J. Distribution of obestatin and ghrelin in human tissues: immunoreactive cells in the gastrointestinal tract, pancreas, and mammary glands. J Histochem Cytochem 2008; 56: 793-801.

14. Gourcerol G, St-Pierre DH, Tache Y. Lack of obestatin effects on food intake: should obestatin be renamed ghrelin-associated peptide (GAP)?. Regul Pept 2007; 141: 1-7.

15. Koc M, Kumral ZN, Ozkan N, Memi G, Kacar O, Bilsel S, et al. Obestatin improves ischemia/reperfusion-induced renal injury in rats via its antioxidant and anti-apoptotic effects: role of the nitric oxide. Peptides 2014; 60: 23-31.

16. Pamukcu O, Kumral ZN, Ercan F, Yegen BC, Ertem D. Anti-inflammatory effect of obestatin and ghrelin in dextran sulfate sodium-induced colitis in rats. J Pediatr Gastroenterol Nutr 2013; 57: 211-8.

17. Sen LS, Karakoyun B, Yegen C, Akkiprik M, Yuksel M, Ercan F, et al. Treatment with either obestatin or ghrelin attenuates mesenteric ischemia-reperfusion-induced oxidative injury of the ileum and the remote organ lung. Peptides 2015; 71: 8-19.

18. Gao XY, Kuang HY, Liu XM, Duan P, Yang Y, Ma ZB. Circulating ghrelin/obestatin ratio in subjects with Helicobacter pylori infection. Nutrition 2009; 25: 506-11.

19. Ulasoglu C, Isbilen B, Doganay L, Ozen F, Kiziltas S, Tuncer I. Effect of Helicobacter pylori eradication on serum ghrelin and obestatin levels. World J Gastroenterol 2013; 19: 2388-94.

20. Dembinski A, Warzecha Z, Ceranowicz P, Cieszkowski J, Dembinski M, Ptak-Belowska A, et al. Administration of obestatin accelerates the healing of chronic gastric ulcers in rats. Med Sci Monit 2011; 17: BR196-200.

21. Habara H, Hayashi Y, Inomata N, Niijima A, Kangawa K. Organ-specific activation of the gastric branch of the efferent vagus nerve by ghrelin in urethane-anesthetized rats. J Pharmacol Sci 2014; 124: 31-9.

22. Imeryuz N, Yegen BC, Bozkurt A, Coskun T, Villanueva-Penacarrillo ML, Ulusoy NB. Glucagon-like peptide1 inhibits gastric emptying via vagal afferent-mediated central mechanisms. Am J Physiol 1997; 273: G920-7.

23. Date Y. Ghrelin and the vagus nerve. Methods Enzymol 2012; 514: 261-9.

24. Sarnik S, Hofirek I, Sochor O. Laser Doppler fluxmetry. Biomed Pap Med Fac Univ Palacky Olomouc Czech Repub 2007; 151: 143-6.

25. Bradley PP, Priebat DA, Christensen RD, Rothstein G. Measurement of cutaneous inflammation: estimation of neutrophil content with an enzyme marker. J Invest Dermatol 1982; 78: 206-9. 
26. Hillegass LM, Griswold DE, Brickson B, Albrightson-Winslow C. Assessment of myeloperoxidase activity in whole rat kidney. J Pharmacol Methods 1990; 24: 285-95.

27. Ozveri ES, Bozkurt A, Haklar G, Cetinel S, Arbak S, Yegen C, et al. Estrogens ameliorate remote organ inflammation induced by burn injury in rats. Inflamm Res 2001; 50: 585-91.

28. Ajeigbe K, Oladejo E, Emikpe B, Asuk A, Olaleye S. The dual modulatory effect of folic acid supplementation on indomethacin-induced gastropathy in the rat. Turk J Gastroenterol 2012; 23: 639-45.

29. Bozkurt A, Yuksel M, Haklar G, Kurtel H, Yegen BC, Alican I. Adenosine protects against indomethacininduced gastric damage in rats. Dig Dis Sci 1998; 43: 1258-63.

30. Takeuchi K. Pathogenesis of NSAID-induced gastric damage: importance of cyclooxygenase inhibition and gastric hypermotility. World J Gastroenterol 2012; 18: 2147-60.

31. Yoshikawa T, Naito Y, Kishi A, Tomii T, Kaneko T, Iinuma S, et al. Role of active oxygen, lipid-peroxidation, and antioxidants in the pathogenesis of gastric-mucosal injury-induced by indomethacin in rats. Gut 1993; 34: 732-7.

32. Koyuncuoglu T, Vizdiklar C, Uren D, Yilmaz H, Yildirim C, Atal SS, et al. Obestatin improves oxidative brain damage and memory dysfunction in rats induced with an epileptic seizure. Peptides 2017; 90: 37-47.

33. Huston JM, Rosas-Ballina M, Xue X, Dowling O, Ochani K, Ochani M, et al. Cholinergic neural signals to the spleen down-regulate leukocyte trafficking via CD11b. J Immunol 2009; 183: 552-9.

34. Hoff DA, Gregersen H, Hatlebakk JG. Mucosal blood flow measurements using laser Doppler perfusion monitoring. World J Gastroenterol 2009; 15: 198-203.

35. Kawano S, Tsuji S. Role of mucosal blood flow: a conceptional review in gastric mucosal injury and protection. J Gastroenterol Hepatol 2000; 15(Suppl.):D1-6.

36. Kamada T, Kawano S, Sato N, Fukuda M, Fusamoto H, Abe H. Gastric mucosal blood distribution and its changes in the healing process of gastric ulcer. Gastroenterology 1983; 84: 1541-6.

37. Lee M. Age-related changes in gastric blood flow in rats. Gerontology 1996; 42: 289-93.

38. Kaneko H, Kaunitz J, Tache Y. Vagal mechanisms underlying gastric protection induced by chemical activation of raphe pallidus in rats. Am J Physiol 1998; 275: G1056-62.

39. Karadi O, Nagy Z, Bodis B, Mozsik G. Atropine-induced gastrointestinal cytoprotection dependences to the intact of vagal nerve against indomethacin-induced gastrointestinal mucosal and microvascular damage in rats. J Physiol Paris 2001; 95: 29-33.

40. Wu R, Dong W, Cui X, Zhou M, Simms HH, Ravikumar TS, et al. Ghrelin down-regulates proinflammatory cytokines in sepsis through activation of the vagus nerve. Ann Surg 2007; 245: 480-6.

41. Sibilia V, Rindi G, Pagani F, Rapetti D, Locatelli V, Torsello A, et al. Ghrelin protects against ethanol-induced gastric ulcers in rats: studies on the mechanisms of action. Endocrinology 2003; 144: 353-9.

42. Fujimiya M, Asakawa A, Ataka K, Kato I, Inui A. Different effects of ghrelin, des-acyl ghrelin and obestatin on gastroduodenal motility in conscious rats. World J Gastroenterol 2008; 14: 6318-26.

43. Kapica M, Zabielska M, Puzio I, Jankowska A, Kato I, Kuwahara A, et al. Obestatin stimulates the secretion of pancreatic juice enzymes through a vagal pathway in anaesthetized rats - preliminary results. J Physiol Pharmacol 2007; 58: 123-30. 